\title{
Soft Tissue Augmentation Using Free Tissue Transfer for Artificial Bone Infection or Skull Bone Sequestration after Neurosurgery
}

\author{
Masayuki Okochi, MD, PhD ${ }^{1}$ Hiromi Okochi, MD, $\mathrm{PhD}^{2}$ Takao Sakaba, MD ${ }^{3}$ Kazuki Ueda, MD, $\mathrm{PhD}^{4}$
}

${ }^{1}$ Department of Plastic and Reconstructive Surgery, Teikyo University, Itabashi-Ku, Tokyo, Japan

2 Department of Plastic and Reconstructive Surgery, Yamanashi University, Chuo, Yamanashi, Japan

${ }^{3}$ Department of Plastic and Reconstructive Surgery, Fuskushima Medical University, Fukushima, Japan

${ }^{4}$ Department of Plastic and Reconstructive Surgery, Jusendo General Hospital, Koriyama, Fukushima, Japan

J Reconstr Microsurg Open 2019;4:e1-e8.
Address for correspondence Masayuki Okochi, MD, PhD, Department of Plastic and Reconstructive Surgery, Teikyo University, 2-11-1 Kaga, Itabashi-Ku, Tokyo 173-8605, Japan (e-mail: oktms-okt@umin.ac.jp).

\begin{abstract}
Background We performed soft tissue augmentation using free flap and secondary cranioplasty combined with soft tissue augmentation for cases with artificial or autologous skull exposure after neurosurgery. We evaluated operative result and the relationship between the cause of infection and the infected site.

Methods Twenty-four patients were included. Data included age, sex, indications for neurosurgery, causes of infection, infection sites, medical comorbidities, time between last neurosurgery and reconstruction, types of reconstruction, and types of secondary cranioplasty.

Results The causes of neurosurgery were subarachnoid hemorrhage $(n=9)$, trauma $(n=5)$, brain tumor $(n=5)$, brain hemorrhage $(n=3)$, and meningioma $(n=3)$. The mean size of infected bone was $67.3 \mathrm{~cm}^{2}$. The mean duration between last neurosurgery and reconstruction was 5.2 years. Types of infected bone were artificial bone $(n=19)$ and autologous skull $(n=6)$. The soft tissue augmentation was performed using latissimus dorsi myocutaneous flap $(n=14)$ and anterolateral thigh flap $(n=10)$. The infection sites were the frontal $(n=13)$, temporal $(n=4)$, parietal $(n=4)$, and occipital regions $(n=4)$. Bone defects included the frontal sinus in all patients who had infections in the frontal region. The patients who had infections in

\section{Keywords}

- scalp reconstruction

- neurosurgery

- cranioplasty non-frontal region received multiple surgeries $(n=7)$. Nine patients received secondary cranioplasty using custom-made hydroxyapatite block.

Conclusion To achieve good results during soft tissue augmentation, the cause of infection should be eliminated.
\end{abstract}

Artificial or autologous bone infection after neurosurgery may decrease patients' quality of life ${ }^{1-8}$ because some patients also suffer from meningitis or severe abscesses ${ }^{1,2}$ and have to undergo removal of the infected bone. ${ }^{3-8}$ It is important to improve the quality of life in such patients. Some authors have reported scalp reconstruction using large local flaps ${ }^{9-12}$ or conservative treatments. ${ }^{2,13}$ Local flap transfer is useful for patients whose general condition is unstable. Conversely, after local flap transfer, scar formation can be seen on the scalp, and such patients' soft tissue and scalp can suffer damage or received

September 24, 2018 accepted after revision November 27, 2018
DOI https://doi.org/

10.1055/s-0039-1678702. ISSN 2377-0813.
Copyright $\odot 2019$ by Thieme Medical Publishers, Inc., 333 Seventh Avenue, New York, NY 10001, USA. Tel: +1(212) 584-4662.
License terms

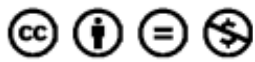


atrophy. Some authors have reported successful scalp reconstruction using free flap transfer. ${ }^{14-17}$ Free flap transfer is useful for patients with large scalp and soft tissue defects. To perform secondary cranioplasty safely, the cause of infection should be preoperatively eliminated. We believe performing soft tissue augmentation using free flap transfer before performing secondary cranioplasty is very effective. A few reports have analyzed the causes of skull infection and ways of preventing them. In this report, a retrospective study was conducted to evaluate the causes of neurosurgery, infected sites, materials used, complications, and outcomes of soft tissue augmentation, duraplasty, and cranioplasty. We also described the benefits of soft tissue augmentation using free flap transfer.

\section{Methods}

This study included 24 patients ( 14 men and 10 women) who underwent free tissue transfer for artificial or autologous bone exposure due to infection between April 2000 and
December 2017. The mean duration between primary cranioplasty and our surgery was $5.4 \pm 7.3$ months (range: 1 week-27 years). Patient details are shown in -Table 1. To evaluate the causes of skull infection, patients were divided into two groups according to the location of infection (frontal group and non-frontal group).

\section{Surgical Technique: First Stage}

Surgery was performed under general anesthesia by oral intubation. The incision was made at the scar of the last neurosurgery. The scalp flap was spared as much as possible. The scalp flap, infected bone, surgical plates, and screws were removed completely. All synthetic materials, autologous bone grafts, and nasal mucosa in the frontal sinus were removed. The superficial temporal artery and vein were dissected. The bone defect size was measured, and then, the flap size was decided. Skin paddle should be larger than the bone defects even in patients who had small skin defects. The flap size was increased if the bone defect included the frontal sinus. In patients who had infection of the dura or

Table 1 Patients profile

\begin{tabular}{|c|c|c|c|c|c|c|c|c|}
\hline & Age & Gender & Location & Cause & $\begin{array}{l}\text { Skull } \\
\text { defect } \\
\left(\mathrm{cm}^{2}\right)\end{array}$ & $\begin{array}{l}\text { Interval between } \\
\text { infection and soft tissue } \\
\text { augmentation (mo) }\end{array}$ & $\begin{array}{l}\text { Primary } \\
\text { cranioplasty }\end{array}$ & $\begin{array}{l}\text { Primary } \\
\text { duraplasty }\end{array}$ \\
\hline 1 & 63 & Male & Frontal & Trauma & 42 & 5.00 & PMMA & $\mathrm{FL}$ \\
\hline 2 & 67 & Male & Frontal & $\mathrm{ICH}$ & 56 & 10.00 & PMMA & $\mathrm{FL}$ \\
\hline 3 & 46 & Male & Frontal & Trauma & 72 & 1.00 & PMMA & $\mathrm{FL}$ \\
\hline 4 & 40 & Male & Frontal & Trauma & 80 & 10.00 & PMMA & PTFE \\
\hline 5 & 60 & Male & Frontal & $\mathrm{ICH}$ & 80 & 0.04 & PMMA & PTFE \\
\hline 6 & 70 & Male & Frontal & $\mathrm{ICH}$ & 28 & 0.25 & PMMA & $\mathrm{FL}$ \\
\hline 7 & 61 & Male & Frontal & BT & 90 & 5.00 & $\mathrm{HA}$ & $\mathrm{FL}$ \\
\hline 8 & 36 & Male & Frontal & Trauma & 81 & 27.00 & PMMA & PTFE \\
\hline 9 & 69 & Male & Frontal & $\mathrm{ICH}$ & 80 & 0.25 & Skull & $\mathrm{FL}$ \\
\hline 10 & 70 & Male & Frontal & $\mathrm{ICH}$ & 100 & 19.00 & PMMA & PTFE \\
\hline 11 & 60 & Female & Frontal & $\mathrm{ICH}$ & 60 & 5.00 & PMMA & $\mathrm{FL}$ \\
\hline 12 & 48 & Female & Frontal & Trauma & 36 & 2.00 & PMMA & $\mathrm{FL}$ \\
\hline 13 & 46 & Female & Frontal & $\mathrm{ICH}$ & 64 & 5.00 & PMMA & PTFE \\
\hline 14 & 32 & Male & Temporal & $\mathrm{ICH}$ & 80 & 17.00 & PMMA & PTFE \\
\hline 15 & 78 & Female & Temporal & $\mathrm{ICH}$ & 96 & 0.08 & PMMA & PTFE \\
\hline 16 & 72 & Female & Temporal & $\mathrm{ICH}$ & 120 & 9.00 & PMMA & PTFE \\
\hline 17 & 85 & Female & Temporal & $\mathrm{ICH}$ & 54 & 0.08 & Skull & PGA \\
\hline 18 & 20 & Male & Parietal & BT & 64 & 0.02 & Skull & PGA \\
\hline 19 & 70 & Female & Parietal & BT & 63 & 0.17 & PMMA & PTFE \\
\hline 20 & 60 & Female & Parietal & BT & 64 & 1.00 & PMMA & $\mathrm{FL}$ \\
\hline 21 & 21 & Female & Parietal & BT & 49 & 13.00 & PMMA & $\mathrm{FL}$ \\
\hline 22 & 72 & Male & Occipital & BT & 56 & 0.08 & PMMA & PTFE \\
\hline 23 & 59 & Male & Occipital & $\mathrm{ICH}$ & 72 & 0.23 & Skull & PTFE \\
\hline 24 & 3 & Female & Occipital & BT & 25 & 0.08 & Skull & $\mathrm{FL}$ \\
\hline
\end{tabular}

Abbreviations: BT, brain tumor; FL, fascia lata; HA, hydroxyapatite; ICH, intracranial hemorrhage; PGA, polyglycolic acid; PMMA, polymethylmethacrylate; PTFE, polytetrafluoroethylene. 
artificial dura, they were also removed. In addition, the fascia lata or vascularized fascia along with the anterolateral thigh (ALT) flap was used for the reconstruction of the dura. Dural reconstruction was performed before flap fixation. The skin flap was fixed temporarily, and vascular anastomosis was performed. The artery and vein of the vascular pedicle were anastomosed in an end-to-end fashion using 9-0 nylon sutures to the superficial temporal artery and vein. After anastomosis, the separation of the nasal cavities from the intracranial cavities was performed using the skin paddle of the flap. The flap was de-epithelized except for the region of scalp flap defect. The flap was covered with the scalp flap and fixed. A suction drain was placed under the scalp flap.

\section{Surgical Technique: Second Stage}

We performed secondary cranioplasty for patients who opted to receive it. Secondary cranioplasty was performed after all abscess formation or ulceration of scalp were not observed. Surgery was performed under general anesthesia by oral intubation. Before secondary cranioplasty, a tissue expander was inserted for patients who had a lack of scalp tissue. The custom-made hydroxyapatite (HA) block was used as an implant. The scalp or forehead flap was elevated with the free flap that had been transferred in the first stage. The HA block was fixed to the cranial defect and covered with the scalp flap. Suction drains were placed under the scalp flap.

\section{Statistical Analysis}

For our patients, differences in age, the size of bone defect, and the duration of preoperative infection between the frontal and non-frontal groups were analyzed by MannWhitney's $U$ test. The ratios of the causes of primary neurosurgery, primary cranioplasty, and primary duraplasty between the frontal and non-frontal groups were evaluated using a chi-square test or Fisher's exact test. All calculations were performed using statistical software (SPSS, IBM Japan, Tokyo, Japan), and $p<0.05$ was considered significant.

\section{Case Report}

\section{Case 1}

A 32-year-old man underwent lateral craniotomy and duraplasty using polytetrafluoroethylene (PTFE) for a subarachnoid hemorrhage. The patient received primary cranioplasty using polymethylmethacrylate (PMMA). However, 2 weeks later, the patient had phlegmon in the temporal region of the scalp. The skull made from PMMA was removed. However, an abscess arose from the artificial dura. One year after the removal of the PMMA skull, the patient was referred to our department; he presented with a skin defect and exposure of the artificial dura ( - Fig. 1). The defect of the scalp contained mastoid cells. Debridement, removal of the PTFE dura, and duraplasty using the fascia lata were performed. Soft tissue augmentation was performed using the latissimus dorsi myocutaneous (LDMC) flap (-Figs. 2 and 3). A $15 \times 12-\mathrm{cm}$ LDMC was harvested from the right side. The thoracodorsal artery and vein were anastomosed to the superficial temporal artery and vein. Seven months after soft tissue

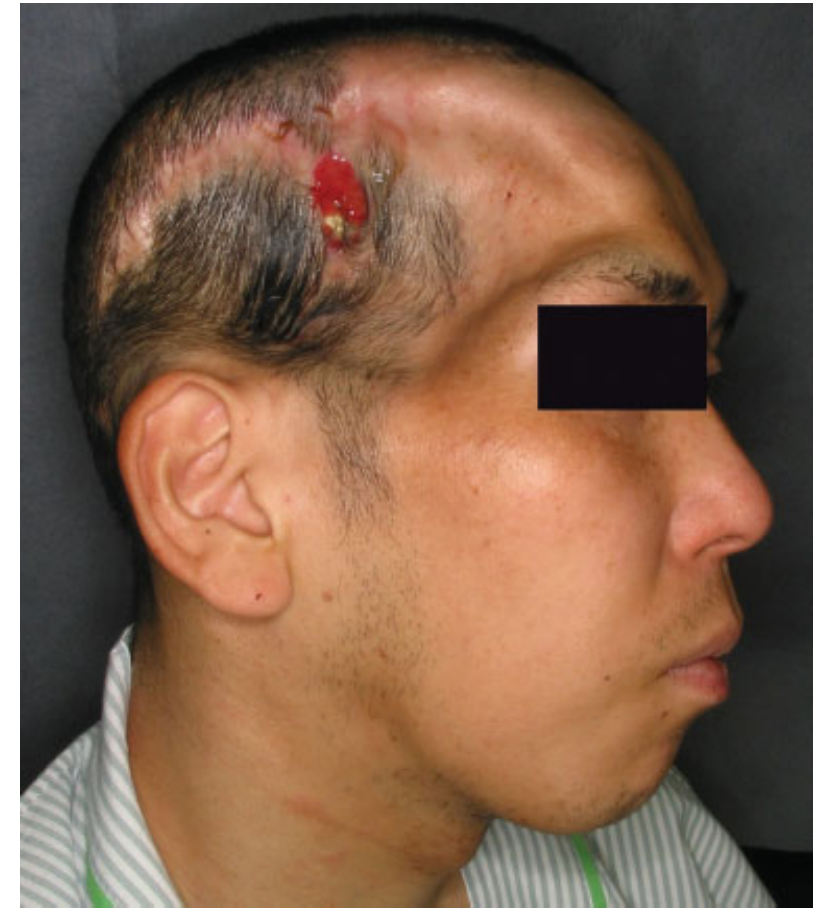

Fig. 1 Preoperative view of case 1. One year after the removal of the artificial skull, the patient was referred to our department; he presented with a skin defect and exposure of the artificial dura.

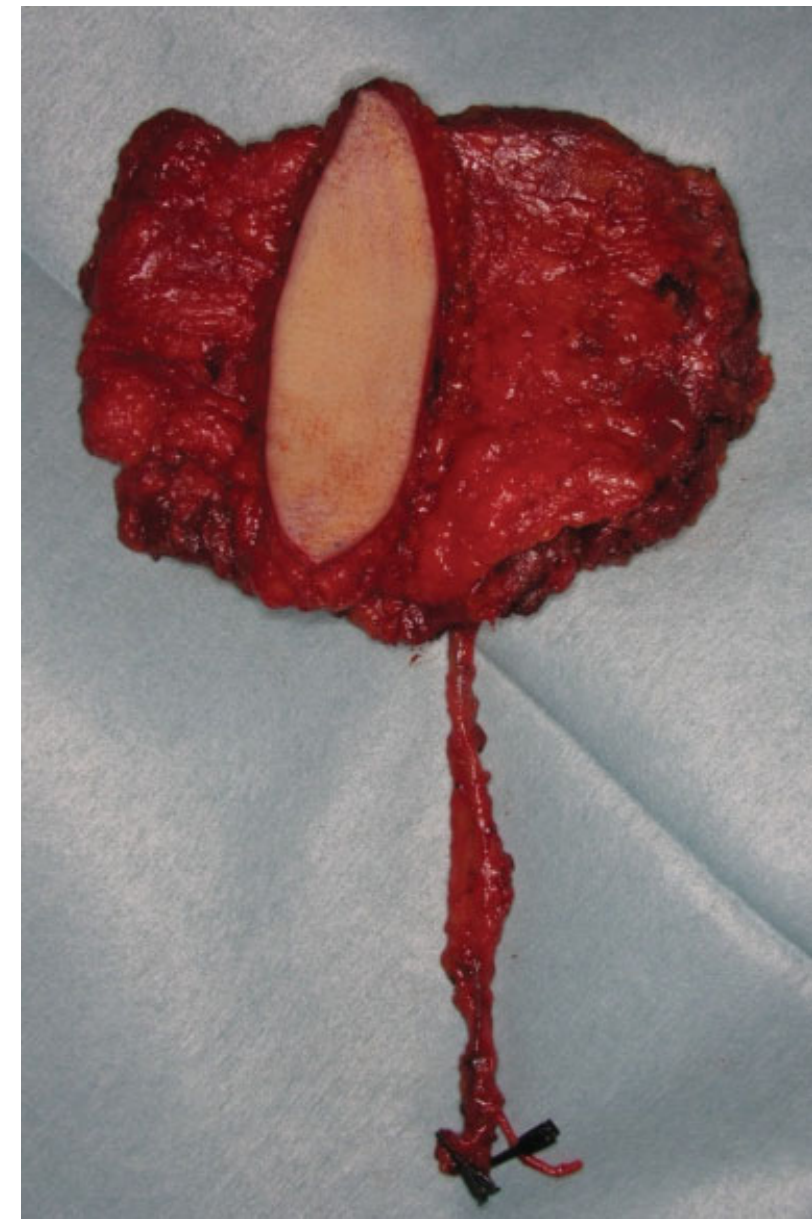

Fig. 2 A $15 \times 12$-cm latissimus dorsi myocutaneous flap was harvested from the right side. 


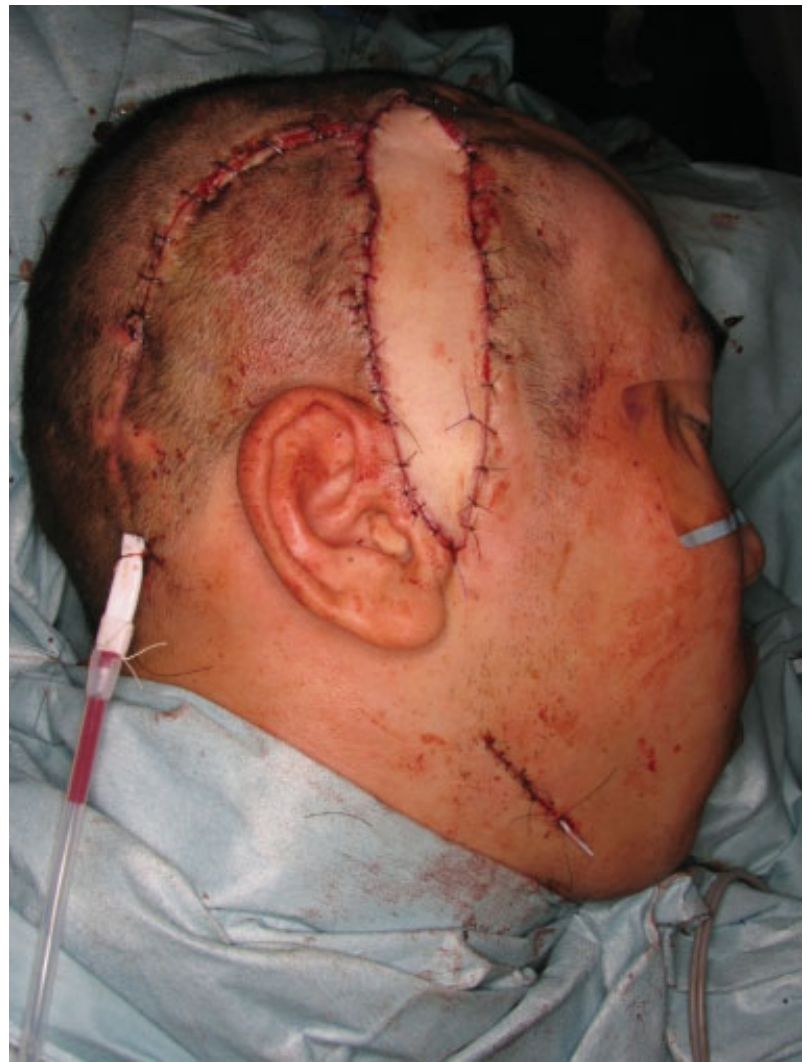

Fig. 3 The soft tissue augmentation was performed. The latissimus dorsi myocutaneous flap was covered with scalp flap.

augmentation, secondary cranioplasty was performed using HA (-Fig. 4). Four years after secondary cranioplasty, recurrence of the exposure of HA was not observed (-Fig. 5).

\section{Case 2}

A 40-year-old man received a severe contusion of the frontal region ( - Fig. 6) and underwent debridement and removal of the frontal bone. Six months after debridement, cranioplasty

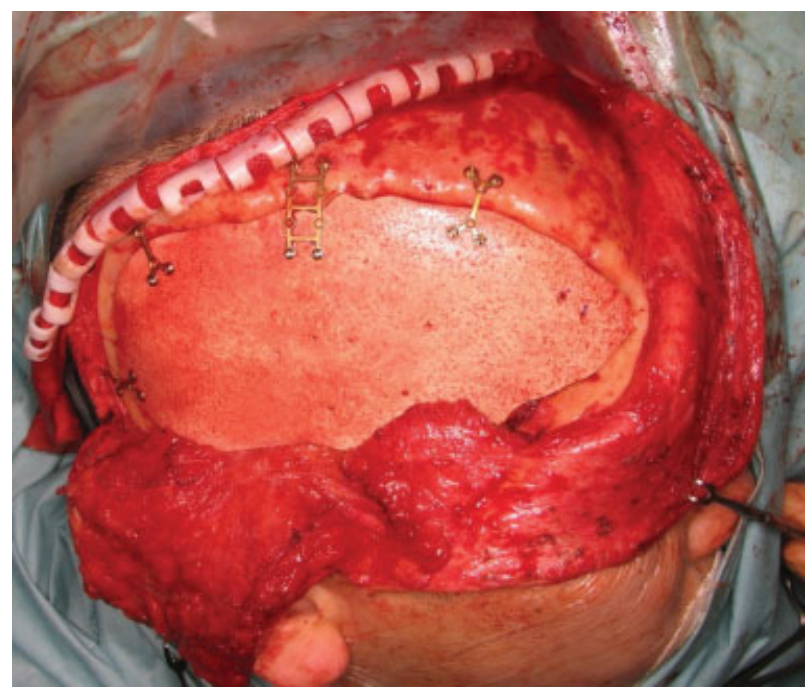

Fig. 4 Seven months after soft tissue augmentation, secondary cranioplasty was performed using custom-made hydroxyapatite block.

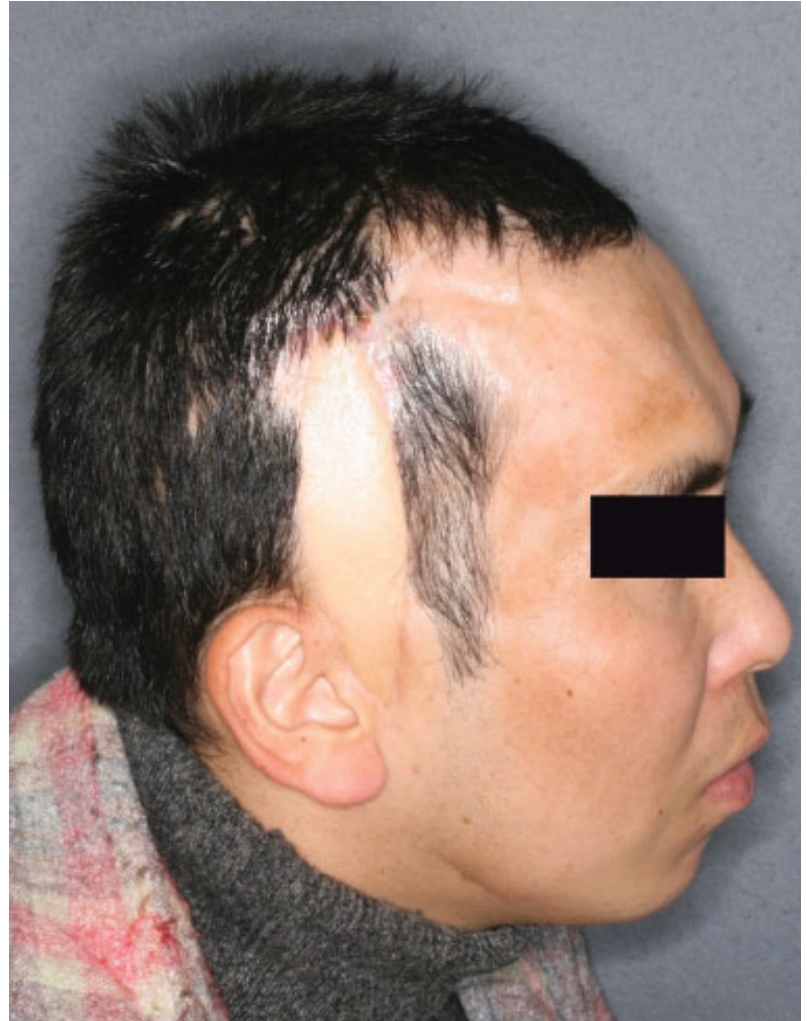

Fig. 5 Final result of case 1. Four years after secondary cranioplasty, recurrence of the exposure of artificial skull was not observed.

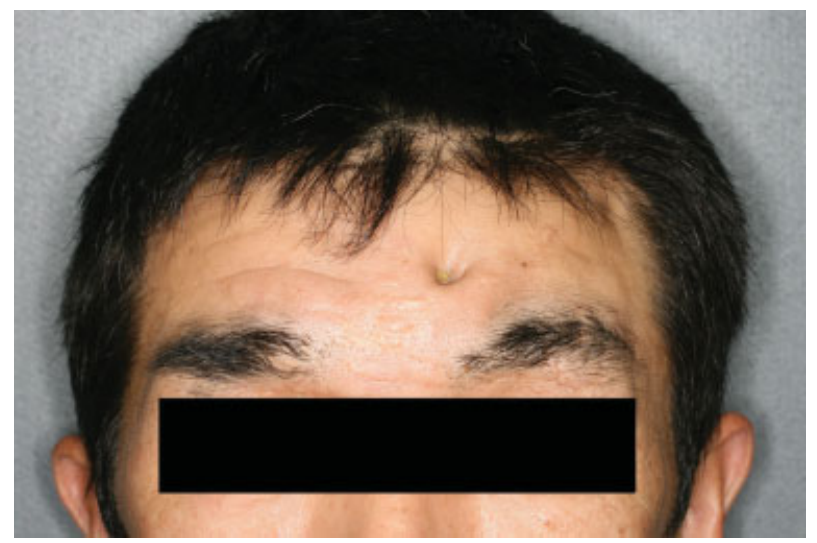

Fig. 6 A 40-year-old man had an infection of artificial skull, and he was referred to our hospital.

was performed using PMMA. However, 1 month after primary cranioplasty, an infection was observed in the forehead region, and he was referred to our hospital ( - Fig. 6). Debridement and soft tissue augmentation were performed using ALT $(15 \times 9 \mathrm{~cm})$. The defect of the skull contained the frontal sinus ( - Fig. 7). The separation of frontal sinus was also performed using ALT (-Fig. 8). Recipient vessels were the left superficial temporal artery and vein. Six months after soft tissue augmentation, secondary cranioplasty was performed using HA (-Fig. 9). Five years after secondary cranioplasty, recurrence of the exposure of HA was not observed (-Fig. 10). 


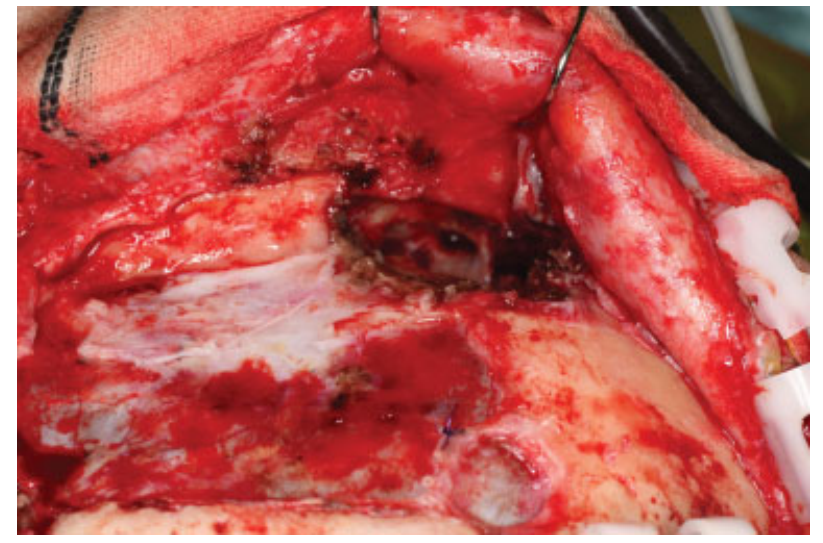

Fig. 7 The defect of the skull contained the frontal sinus.

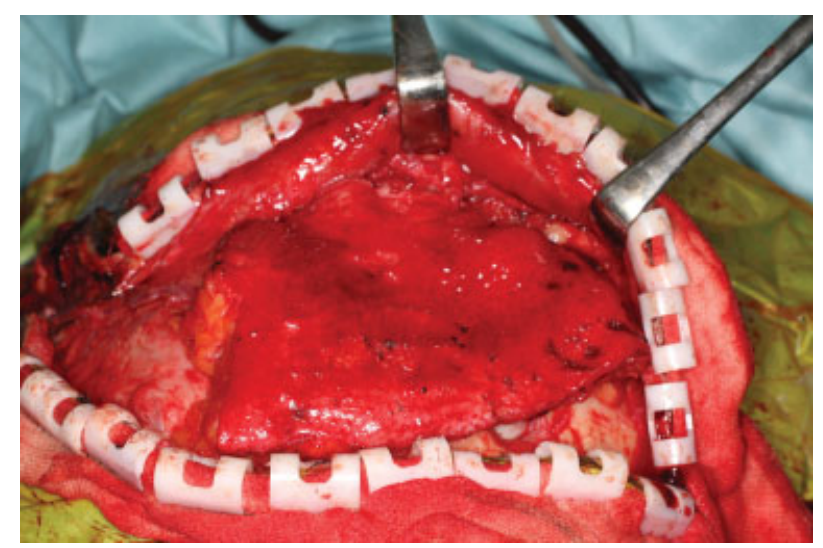

Fig. 8 Debridement, soft tissue augmentation, and separation of frontal sinus were performed using anterolateral thigh flap.

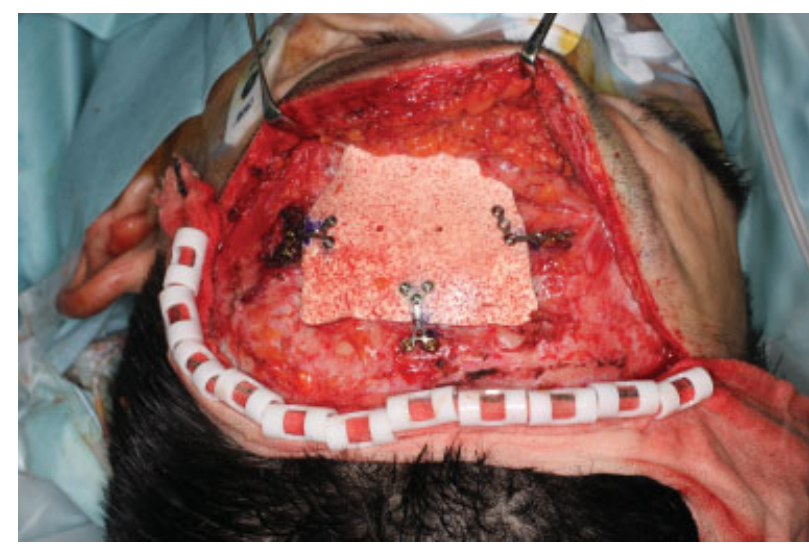

Fig. 9 The secondary cranioplasty was performed using custom-made hydroxyapatite block.

\section{Results}

The indications of primary neurosurgery were intracranial hemorrhage in 12 cases: brain tumor in 7 cases and trauma in 5 cases. The locations of the infected bone were the frontal region in 13 cases, temporal region in 4 cases, parietal region in 4 cases, and occipital region in 4 cases. The mean bone defect size was $67.2 \mathrm{~cm}^{2}$ (range: $25-120 \mathrm{~cm}^{2}$ ). Primary cranioplasty was performed using PTFE in 18 cases, autologous skull in 5 cases, and HA block in 1 case. Primary dural reconstruction

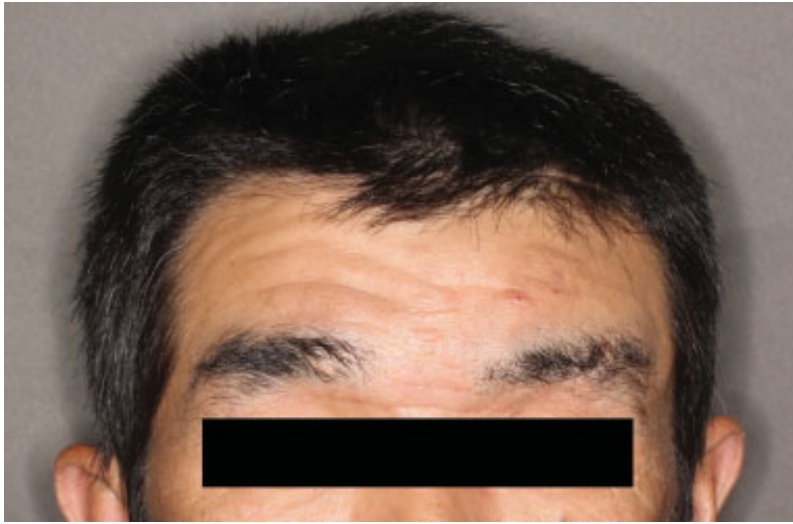

Fig. 10 Result of case 2. Five years after secondary cranioplasty, recurrence of the exposure of artificial skull was not observed.

Table 2 Procedure of soft tissue augmentation and secondary cranioplasty

\begin{tabular}{|l|l|}
\hline \multicolumn{2}{|l|}{ Soft tissue augmentation } \\
\hline LD & 14 \\
\hline ALT & 10 \\
\hline Secondary duraplasty & 11 \\
\hline FL & 5 \\
\hline vFL & 9 \\
\hline Secondary cranioplasty & $7.1 \pm 1.1$ \\
\hline HA & $8.7 \pm 2.1$ \\
\hline $\begin{array}{l}\text { Interval between soft tissue } \\
\text { augmentation and secondary } \\
\text { cranioplasty (mo) }\end{array}$ & \\
\hline Follow-up (y) &
\end{tabular}

Abbreviations: ALT, anterolateral thigh; FL, fascia lata; HA, hydroxyapatite; LD, latissimus dorsi; vFL, vascularized fascia lata.

was performed using the fascia lata in 15 cases, expanded PTFE in 7 cases, and polyglycolic acid in 2 cases ( - Table 1 ). LDMC and ALT were used for soft tissue reconstruction in 14 and 10 cases, respectively. Sixteen dural reconstructions were performed using the free fascia lata $(n=11)$ or the fascia lata with ALT $(n=5)$. Secondary cranioplasty using a custom-made HA block was performed in nine cases. The mean duration between soft tissue augmentation using free flap transfer and secondary cranioplasty was $7.1 \pm 1.1$ months (range: 611 months). The mean follow-up period of patients who received secondary cranioplasty was $8.7 \pm 2.1$ years (range: $5-12$ years) (-Table 2 ).

Statistically, no significant differences were observed between the frontal group $(n=13)$ and non-frontal group $(n=11)$ regarding gender $(p=0.095)$, age $(p=0.503)$, size of defect $(p=0.943)$, cause $(p=0.693)$, material of primary cranioplasty $(p=0.170)$, or material of primary duraplasty $(p=0.160)$. The percentage of patients whose bone defect included sinus or air cells was significantly higher in the frontal group than in the non-frontal group $(p<0.001)$. Conversely, the percentage of patients receiving more than two neurosurgeries 
Table 3 Statistical analysis between frontal group and nonfrontal group

\begin{tabular}{|c|c|c|c|}
\hline & $\begin{array}{l}\text { Frontal } \\
\text { group }\end{array}$ & $\begin{array}{l}\text { Non-frontal } \\
\text { group }\end{array}$ & $p$-Value \\
\hline \multicolumn{4}{|l|}{ Gender } \\
\hline Male & 10 & 4 & \multirow[t]{2}{*}{0.095} \\
\hline Female & 3 & 7 & \\
\hline Age & $56.6 \pm 11.9$ & $52.0 \pm 27.9$ & 0.503 \\
\hline $\begin{array}{l}\text { Size of bone } \\
\text { defect }\end{array}$ & $66.8 \pm 21.7$ & $67.5 \pm 25.0$ & 0.943 \\
\hline \multicolumn{4}{|c|}{ Cause of craniotomy } \\
\hline $\begin{array}{l}\text { Intra cranial } \\
\text { hemorrhage }\end{array}$ & 8 & 5 & \multirow[t]{2}{*}{0.695} \\
\hline Other & 6 & 6 & \\
\hline \multicolumn{4}{|c|}{ Primary cranioplasty } \\
\hline Artificial scalp & 12 & 7 & \multirow[t]{2}{*}{0.142} \\
\hline $\begin{array}{l}\text { Autologous } \\
\text { scalp }\end{array}$ & 1 & 4 & \\
\hline \multicolumn{4}{|c|}{ Primary duraplasty } \\
\hline Artificial dura & 3 & 6 & \multirow[t]{2}{*}{0.206} \\
\hline $\begin{array}{l}\text { Autologous } \\
\text { fascia lata }\end{array}$ & 10 & 5 & \\
\hline \multicolumn{4}{|c|}{ Operation before bone exposure } \\
\hline$<2$ & 1 & 7 & \multirow[t]{2}{*}{$0.008^{*}$} \\
\hline $0-1$ & 12 & 4 & \\
\hline \multicolumn{4}{|c|}{ Exposure of intracranial cavity } \\
\hline Yes & 12 & 1 & \multirow[t]{2}{*}{$<0.001^{*}$} \\
\hline No & 1 & 10 & \\
\hline
\end{tabular}

* $p$-Value $<0.05$, in the age and size of defect sections, each value indicates average \pm standard deviation.

before our surgery was significantly higher in the non-frontal group than in the frontal group $(p=0.008)$ ( - Table 3 ).

\section{Discussion}

Skull infection after neurosurgery occurs in approximately $1.1^{2}$ to $8.1 \%$ of all patients. ${ }^{7}$ These patients often suffer from epidural abscesses, meningitis, or stubborn fistulas and have to have the infected bone removed. Some authors have examined the results of secondary cranioplasty and have reported an $\sim 10 \%$ rate of bone infection after secondary cranioplasty. ${ }^{6}$ Fong et al suggested that preoperative radiation, preoperative infection, and poor soft tissue coverage increased the risk of infection after secondary cranioplasty. ${ }^{6}$ In our study, the causes of infection after cranioplasty differed depending on the location of the cranial defect. In the frontal group, improper treatment of the open frontal sinus often caused the infection and exposure of the skull. Conversely, in the non-frontal group, multiple neurosurgeries often caused skull infection and exposure. Our results suggested that eliminating the cause of infection is a key to successful secondary cranioplasty.

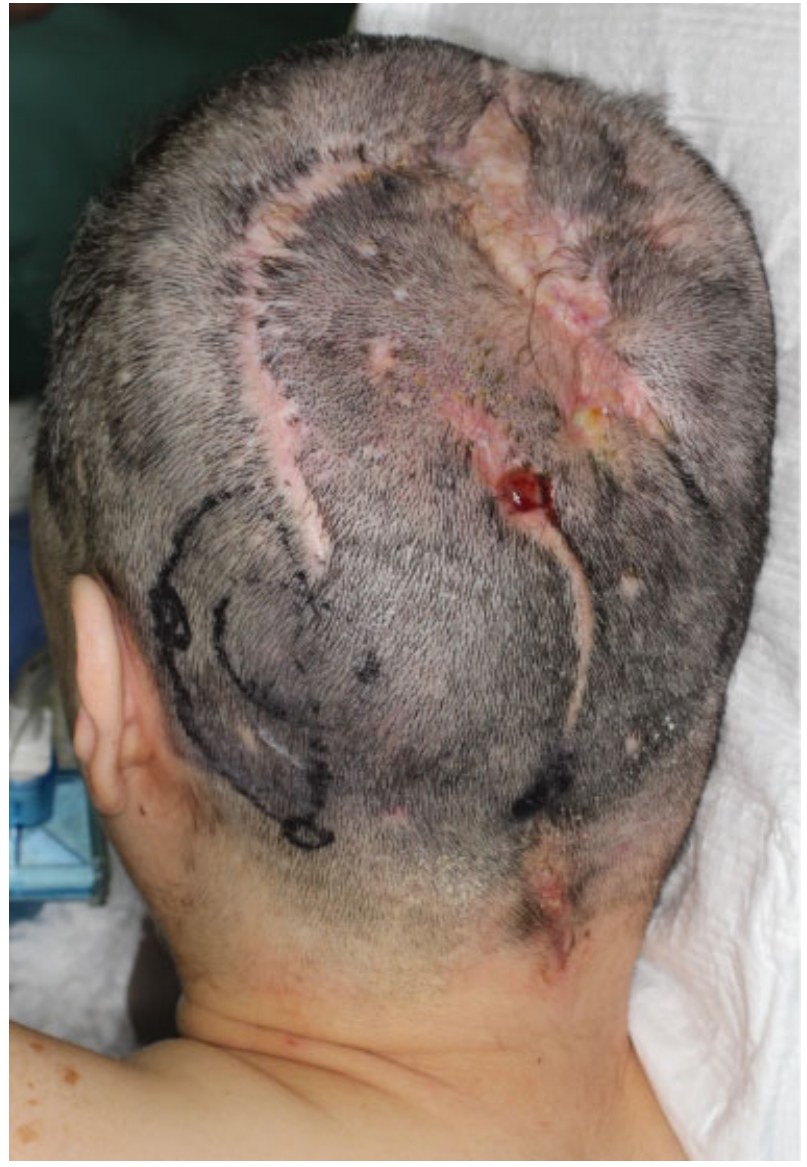

Fig. 11 Patient received local flap transfers for three times. Long and visible scars were observed.

Some authors have reported successful scalp reconstruction using the local flap. Ransom and Jacono performed scalp reconstruction using the bilateral scalping and rotation advancement flaps. ${ }^{9}$ Scalp reconstruction using the single rotation flap, ${ }^{10} \mathrm{~V}$-Y advancement flap, ${ }^{11}$ and double scalping flap $^{12}$ has also been reported. These procedures are very useful in patients whose general condition is unstable. However, such patients are often left with many long scars (-Fig. 11). Atrophy of the scalp and soft tissue was observed in our cases. It would be very difficult to perform secondary cranioplasty for such cases. ${ }^{13}$ We felt the need for the augmentation of the scalp using well-vascularized tissue.

Free muscle flap transfer is a useful procedure for scalp reconstruction; it employs the use of LDMC, ${ }^{14,15}$ rectus abdominis muscle flap, ${ }^{16}$ and vastus lateralis muscle flap, ${ }^{17}$ which are known as workhorse flaps. Muscle flaps contain rich vascular network and are easy to harvest. However, postoperative atrophy of muscle flaps has been reported. ${ }^{18-20}$ Sakamoto et al evaluated postoperative changes in muscle cutaneous flap volume and reported that the volume of the muscle was significantly decreased at 12 months postoperatively. ${ }^{18}$ The thinning of the flap may lead to scalp exposure. Scalp reconstructions using the perforator flap, ${ }^{21,22}$ the fasciocutaneous flap, ${ }^{23}$ and the fascial flap ${ }^{24}$ have also been reported. We used the LDMC and ALT rather than the muscle flap for soft tissue augmentation. These flaps are easy to harvest, and $>10$ - 
cm-wide flaps can be harvested. All our cases showed scalp and soft tissue atrophy preoperatively. Four of the 11 patients in the non-frontal group received more than three neurosurgeries. In our cases, scalp and forehead skin was spared as much as possible, and the scalp flap or forehead flap was elevated gently. Moreover, our flaps were larger than the bone defects even in patients who had small skin defects. The flap was transferred to the bone defect, de-epithelialized, and then covered with the scalp or forehead flap.

Yoshioka reported the importance of the separation of the frontal sinus. ${ }^{14}$ Therefore, frontal sinusitis may lead to the infection of the cranioplasty site. All patients in the frontal group showed frontal sinus exposure and frontal sinusitis. The separation of the intracranial cavity from the nasal space was required in all frontal-group patients. Several authors have reported the usefulness of the pericranial and galealpericranial flaps for the separation of the nasal and intracranial cavities. ${ }^{25,26}$ In our cases, an incision was made on the superficial artery during neurosurgery, and we could not confirm its patency in the peripheral region. Free flap transfer was useful in such cases as it allowed for the separation of the nasal and intracranial cavities using a part of the flap. To perform secondary cranioplasty, the forehead flap or scalp flap was elevated with the soft tissue of the free flap.

In our cases, the mean interval between soft tissue augmentation and secondary cranioplasty was 7.8 months. There is no guideline on how long one should wait to undergo secondary cranioplasty after the elimination of infection. Some authors have reported that the interval should be approximately 3 to 12 months. ${ }^{14,27}$ In our cases, six patients received secondary cranioplasty. Yoshioka performed cranioplasty within 3 months of debridement. ${ }^{14}$ Conversely, we performed secondary cranioplasty more than 6 months after soft tissue augmentation. In addition, we inserted a tissue expander 7 months after soft tissue augmentation for two patients. In this report, we could not investigate the ideal interval between soft tissue augmentation and secondary cranioplasty. We believe further study is needed in this regard.

In our cases, a custom-made HA block was used for secondary cranioplasty. HA is commonly used for cranioplasty. ${ }^{28}$ Reddy et al reported that there were no significant differences in the rate of postoperative infection between autologous bone and other materials including HA. ${ }^{29}$ Some authors have reported that HA was more beneficial than titanium in terms of the infection rate and the neurological outcome, ${ }^{29-31}$ and HA block also exhibited good osteoconduction and biocompatibility. ${ }^{29-32}$ In our cases, no case had exposure to or infection of HA even after an 8.7-year follow-up period. Reddy et al reported one-stage reconstruction of soft tissue and skull composite defects using LDMC with vascularized rib grafts. Rodriguez et al reported skull reconstruction using a fibra bone flap. ${ }^{33}$ Cranioplasty using these flaps is also useful. However, flap setting and vein grafting are sometimes difficult. To avoid these difficulties, we performed cranioplasty after soft tissue augmentation.

We performed soft tissue augmentation and dural reconstruction for 16 patients. In our cases, all 16 patients had epidural abscess and capsule formation after the removal of the infected dura. Hata et al reported that additional dural reconstruction is not required for such patients. ${ }^{34}$ However, we performed dural reconstruction because our patients had cerebrospinal fluid leakage. Five of 16 patients had severe abscess. To prevent from postoperative subdural infection, we performed free ALT flap transfer with the vascularized fascia.

Erickson et al reported that a closed suction-irrigation system could save the infected bone. ${ }^{35}$ However, we removed all the infected bone because the removal of infected bone is considered the standard treatment. There is no guideline on whether fascia should be vascularized or whether infected materials should be removed. We believe further study is required in this regard.

\section{Conclusion}

To achieve good results during soft tissue augmentation, the cause of infection should be eliminated. The separation of frontal sinus or air cell and soft tissue augmentation using free flap is effective for the secondary cranioplasty.

Conflict of Interest

None declared.

\section{References}

1 Kourbeti IS, Vakis AF, Ziakas P, et al. Infections in patients undergoing craniotomy: risk factors associated with post-craniotomy meningitis. J Neurosurg 2015;122(05):1113-1119

2 Blomstedt GC. Infections in neurosurgery: a retrospective study of 1143 patients and 1517 operations. Acta Neurochir (Wien) 1985; 78(3-4):81-90

3 Bobinski L, Koskinen L-OD, Lindvall P. Complications following cranioplasty using autologous bone or polymethylmethacrylateretrospective experience from a single center. Clin Neurol Neurosurg 2013;115(09):1788-1791

4 Punchak M, Chung LK, Lagman C, et al. Outcomes following polyetheretherketone (PEEK) cranioplasty: systematic review and meta-analysis. J Clin Neurosci 2017;41:30-35

5 Jonkergouw J, van de Vijfeijken SE, Nout E, et al. Outcome in patient-specific PEEK cranioplasty: a two-center cohort study of 40 implants. J Craniomaxillofac Surg 2016;44(09):1266-1272

6 Fong AJ, Lemelman BT, Lam S, Kleiber GM, Reid RR, Gottlieb LJ. Reconstructive approach to hostile cranioplasty: a review of the University of Chicago experience. J Plast Reconstr Aesthet Surg 2015;68(08):1036-1043

7 Tsang AC, Hui VK, Lui WM, Leung GK. Complications of postcraniectomy cranioplasty: risk factor analysis and implications for treatment planning. J Clin Neurosci 2015;22(05):834-837

8 Brommeland T, Rydning PN, Pripp AH, Helseth E. Cranioplasty complications and risk factors associated with bone flap resorption. Scand J Trauma Resusc Emerg Med 2015;23:75

9 Ransom ER, Jacono AA. Double-opposing rotation-advancement flaps for closure of forehead defects. Arch Facial Plast Surg 2012; 14(05):342-345

10 Umman P, Pillai VG, Abraham PM, Varkey RG. Rotation flap closure of moderate size scalp defects - technique and outcome. J Clin Diagn Res 2016;10(11):PD21-PD23

11 Gundeslioglu AO, Selimoglu MN, Doldurucu T, Bekerecioglu M. Reconstruction of large anterior scalp defects using advancement flaps. J Craniofac Surg 2012;23(06):1766-1769 
12 Papadopoulos O, Karypidis D, Moustaki M, et al. Double scalping flap: a versatile technique in scalp reconstruction.J Craniofac Surg 2009;20(05):1484-1491

13 Baumeister S, Peek A, Friedman A, Levin LS, Marcus JR. Management of postneurosurgical bone flap loss caused by infection. Plast Reconstr Surg 2008;122(06):195e-208e

14 Yoshioka N. Versatility of the latissimus dorsi free flap during the treatment of complex postcraniotomy surgical site infections. Plast Reconstr Surg Glob Open 2017;5(06):e1355

15 Hierner R, van Loon J, Goffin J, van Calenbergh F. Free latissimus dorsi flap transfer for subtotal scalp and cranium defect reconstruction: report of 7 cases. Microsurgery 2007;27(05):425-428

16 Richards M. Reconstruction of an extensive scalp defect. Br J Plast Surg 1998;51(08):649

17 Tanaka Y, Matsumoto K, Song S, Tajima S, Ohmura T. Reconstruction of a cranial bone defect with hydroxyapatite and free flap transfer. J Craniofac Surg 1997;8(02):141-145

18 Sakamoto Y, Takahara T, Ota Y, et al. MRI analysis of chronological changes in free-flap volume in head and neck reconstruction by volumetry. Tokai J Exp Clin Med 2014;39(01):44-50

19 Bailey BN, Godfrey AM. Latissimus dorsi muscle free flaps. Br J Plast Surg 1982;35(01):47-52

20 Wolff KD, Stiller D. Functional aspects of free muscle transplantation: atrophy, reinnervation, and metabolism. J Reconstr Microsurg 1992;8(02):137-142

21 Ozkan O, Coskunfirat OK, Ozgentas HE, Derin A. Rationale for reconstruction of large scalp defects using the anterolateral thigh flap: structural and aesthetic outcomes. J Reconstr Microsurg 2005;21(08):539-545

22 Chang KP, Lai CH, Chang CH, Lin CL, Lai CS, Lin SD. Free flap options for reconstruction of complicated scalp and calvarial defects: report of a series of cases and literature review. Microsurgery 2010;30(01):13-18

23 Lutz BS, Wei FC, Chen HC, Lin CH, Wei CY. Reconstruction of scalp defects with free flaps in 30 cases. Br J Plast Surg 1998;51(03): 186-190

24 Tenna S, Brunetti B, Aveta A, Poccia I, Persichetti P. Scalp reconstruction with superficial temporal artery island flap: clinical experience on 30 consecutive cases. J Plast Reconstr Aesthet Surg 2013;66(05):660-666

25 Safavi-Abbasi S, Komune N, Archer JB, et al. Surgical anatomy and utility of pedicled vascularized tissue flaps for multilayered repair of skull base defects. J Neurosurg 2016;125(02):419-430

26 Yoshioka N. Modified cranialization and secondary cranioplasty for frontal sinus infection after craniotomy: technical note. Neurol Med Chir (Tokyo) 2014;54(09):768-773

27 Malcolm JG, Rindler RS, Chu JK, Grossberg JA, Pradilla G, Ahmad FU. Complications following cranioplasty and relationship to timing: a systematic review and meta-analysis. J Clin Neurosci 2016;33:39-51

28 Eppley BL. Hydroxyapatite cranioplasty: I. Experimental results from a new quick-setting material. J Craniofac Surg 2003;14(01):85-88

29 Reddy S, Khalifian S, Flores JM, et al. Clinical outcomes in cranioplasty: risk factors and choice of reconstructive material. Plast Reconstr Surg 2014;133(04):864-873

30 Lindner D, Schlothofer-Schumann K, Kern BC, Marx O, Müns A Meixensberger J. Cranioplasty using custom-made hydroxyapatite versus titanium: a randomized clinical trial. J Neurosurg 2017;126(01):175-183

31 Zanotti B, Zingaretti N, Verlicchi A, Robiony M, Alfieri A, Parodi PC. Cranioplasty: review of materials. J Craniofac Surg 2016;27(08): 2061-2072

32 Rosen HM. Porous, block hydroxyapatite as an interpositional bone graft substitute in orthognathic surgery. Plast Reconstr Surg 1989;83(06):985-990, discussion 991-993

33 Rodriguez ED, Stanwix MG, Nam AJ, St Hilaire H, Simmons OP, Manson PN. Definitive treatment of persistent frontal sinus infections: elimination of dead space and sinonasal communication. Plast Reconstr Surg 2009;123(03):957-967

34 Hata N, Hisada K, Torisu R, Suzuki SO, Kameda K, Sasaki T. Foreign body granuloma associated with dura-cranioplasty after resection of convexity meningioma with extracranial extension: case report. Neurol Med Chir (Tokyo) 2011;51(03):236-238

35 Erickson DL, Seljeskog EL, Chou SN. Suction-irrigation treatment of craniotomy infections. Technical note. J Neurosurg 1974;41 (02):265-267 